Seale, C. and Charteris-Black, J. (2008) The interaction of class and gender in illness narratives Sociology 42(3): 453-469

\title{
The interaction of class and gender in illness narratives
}

\begin{abstract}
Perspectives on gender and identity that emphasise variability of performance, local context and individual agency have displaced earlier paradigms. These are now perceived to have supported gender stereotypes and language ideologies by emphasising gender difference and homogeneity within genders. In a secondary analysis of health and illness narratives we explore the interaction of class and gender in individuals' constructions of gendered identity. High social class men perform gender in particularly varied ways and we speculate that this variable repertoire, including the use of what was once termed 'women's language', is linked to a capacity to maintain social distinction and authority. Men's performance of conventional masculinity is often threatened both by the experience of illness and being interviewed about personal experience. Lower social class women in particular demonstrate an intensification of a pre-existing informal family and support group culture, marking successful members by awarding them the accolade of being 'lovely'.
\end{abstract}

Keywords: gender, social class, illness narratives, sociolinguistics

The shift towards a performative view of gender in recent sociology has been marked, resulting in studies that emphasise variability, individual agency and the influence of local context. This has involved a degree of distancing from an earlier 'gender difference' paradigm, variously characterised as essentialist, deterministic, promoting of gender stereotypes, or lacking in an appreciation of contextual and cultural variability (Speer, 2005; Stokoe and Weatherell, 2002). In this paper we present an account of gendered performance within illness narratives that draws on a performative perspective, but which recognises the continuing relevance of elements of the gender difference model, albeit modified by an appreciation of the interaction of social class with gender, and a recognition of the importance of both individual agency and the local context in which accounts are produced

In sociolinguistics, earlier paradigms are commonly characterised (Speer, 2005; Coates, 2004) as moving from an initial view of 'women's language' as deficient in terms of accessing more powerful male ways of communicating, towards a more critical assessment of the role of language in exercising male dominance over women. Sociolinguistic research within a third 'gender difference' paradigm has produced a considerable body of evidence documenting and promoting the idea of male/female difference (Bergvall 1999). Coates (2004) reviews work done from within all three phases of sociolinguistics, which together can we call 'variationist' sociolinguistics to distinguish this from a fourth, performative paradigm. She reviews studies showing that women express feelings, intimacy and mutual support more readily than men, who prefer to discuss impersonal topics like sport or current affairs, albeit sometimes in a manner that generates male solidarity or what Kiesling (2005), writing within the performative paradigm, calls 'homosocial desire'. An important agenda in 'men's 
language', for writers like Coates, is the assertion of male heterosexual identity. Amongst other things, effort has been put into documenting men's quantitative dominance of mixed sex speech situations, their tendency to interrupt or exclude women, their desire to assert their status as knowledge experts or successful achievers.

There has been growing dissatisfaction with the contribution which this variationist research tradition makes to a stereotyped characterisation of men and women inhabiting two cultures (Talbot, 2003). Much empirical work from within the alternative performative paradigm therefore focuses on local 'communities of practice' (Lave and Wenger, 1991; Eckert and Wenger 2005)) that challenge, resist or otherwise deviate from 'hegemonic' forms (Connell, 1995). Thus, quasi-ethnographic sociolinguistic studies of gay men and women, cross dressers, phone sex workers and drag queens proliferate in the journals, emphasising the mutability of gendered performances and the agency of the people concerned. Accompanying this has been a suspicion that much work done within variationist paradigms has placed excessive reliance on the linguistic behaviour of upper and middle class men and women, so that these elite individuals have been made to stand for all (Eckert, 1990; Freed, 1992). For example, an early claim made by Lakoff (1975) was that women were more likely to use 'empty' adjectives for emotional emphasis (we call these 'boosters' in this paper). Lakoff's two key examples are 'divine' and 'charming', clearly words that even in the 1960s and 1970s would have been associated with elite cultures.

Cameron (2003) presents a helpful perspective on this field in her account of language ideologies, in which she notes that variationist representations of gender and language are often used to provide support the popular view, promoted in mass media folklinguistics, that gender differences exist, are complementary and are natural. Cameron marks the ideological status of these beliefs by noting that the content of such popular stereotypes is different across cultures, and across historical periods. The language ideology current in the USA and UK holds that men (particularly if working class) are 'inarticulate, linguistically unskilled' (2003: 454) because of their assumed inability to participate in a public discourse that nowadays emphasises the need for informality, personal intimacy, self revelation, admissions of vulnerability, cooperative rather than competitive interaction - all characteristics that are thought within the variationist paradigm to be the particular skill of women. This view has also been influential within sociology, with Giddens (1994) observing that '[w]omen have prepared the way for an expansion of the domain of intimacy in their role as the emotional revolutionaries of modernity' (1994: 30). The widespread belief that associates these characteristics with women paradoxically allows male politicians (like Tony Blair or Bill Clinton) to exploit this mode of discourse quite effectively in the interests of power, producing 'women's language' in public settings as a way of marking their sensitivity and ordinariness.

Understanding the interaction of people with both gender and class identities is important for gaining an understanding of how cultural capital is deployed in the interests of social advantage and the maintenance of distinction. The sociological study of social class has in the past been associated with a perspective that emphasises the social structural determination of life chances, a perspective that has fallen out of favour as growing interest in the cultural and discursive formation of identity has prioritised race/ethnicity and gender as key sources of variability (Savage, 2000). But 
social inequalities of income, education and occupation actually play an even greater role than they did 30 years ago in determining the life chances of people in the UK and the USA, as evidence of widening discrepancies of income and life expectancy since the 1980s in both countries accumulates (Savage, 2000). Paradoxically, because of growing obligations to understand personal identity as a reflexive personal project, people increasingly resist self-identification with a class position. Thus class is often, in the popular imagination, pronounced to be 'dead' and class-based politics rejected. Public and political awareness of the objective importance of social and income inequality has declined. As Savage argues, drawing on Bourdieu's idea of social capital (1986), social class deserves to be put back into socio-cultural and sociolinguistic analysis if sociologists are to contribute to the demystification of inequalities in modern societies. We present this paper as a small contribution to this effort, through an account of the interaction of class and gender in illness narratives.

\section{Method, methodology and materials}

A selection of 96 qualitative interviews with people experiencing a variety of illness conditions or health issues is analysed for this paper, using a mixed quantitative and qualitative approach designed to produce systematic comparisons across social class and gender, while controlling for other factors that might influence the comparison. The 96 interviews are a sub sample of a large corpus of 1035 interview transcripts purchased for secondary analysis from the DIPEx project (www.dipex.org.uk), a collection of narrative interviews about illness and health experiences collected for display on an associated educational web site. The numbering of the interviews in this paper follows that on the web site, so readers interested to watch and hear these interviewees can do this by visiting the site. Full informed consent was given by interviewees for the use of their transcripts for research purposes.

The sub sample of 96 was selected to enable matched comparisons across gender and social class. All interviewees were categorised by socio-economic category (SEC) according to a three point version of the UK Office for National Statistics scheme (Rose and Pevalin, 2005) that has now replaced an older (Registrar General's) scheme for dividing the population by occupational status, used in numerous studies of social class variation, including the Black Report on health inequalities (Townsend and Davidson, 1982). The 96 interviews were divided into four subgroups of 24 each by SEC and gender, matched with each other by age, type of health/illness condition and gender of interviewer. High SEC interviewees included higher and lower managerial and professional occupations. Low SEC interviewees included intermediate, routine and manual SEC groups. The mean ages for each of the four groups were similar, falling between 50 and 52 years, with a range between 16 and 81. Each group of 24 contained interviews with people speaking about their chronic pain ( 2 interviewees in each group), colorectal cancer (2), depression (4), termination of pregnancy (1), epilepsy (2), heart attack (1), heart failure (3), receiving intensive care (2), lung cancer (4), terminal illness (2), teenage cancer (1). All interviewers were women, except for those concerning depression.

The amount of text in these 96 interviews comprised just under a million words of text, with low SEC men contributing somewhat less than other groups (see the 'total words' in table 1 below). The approach taken to analysis mixed a quantitative and a 
qualitative approach, initially using computer software to provide what we like to think of as an 'aerial view' of word patterns across comparison groups. This involved an initial comparative keyword analysis (Seale et al., 2006) using Wordsmith Tools (Scott, 2005) to establish the words occurring with high or low relative frequencies across comparison groups. Supplementing and extending this, the texts were automatic semantic tagging using WMatrix software (Rayson, 2005) that enabled a further comparative analysis of the frequencies of semantic word groupings. Through writing this up, discussing it together, and investigating the particular contexts in which words were used, the tabulations presented in the quantitative part of this paper were eventually produced.

We are acutely aware of the limitations of unthinking reliance on quantitative or automated analyses of text (Billig, 1988). At the same time, we resist the unthinking dismissal of quantitative approaches to text analysis. Our own procedures involved an awareness of the need to examine the context in which words were being used.

Sometimes, the mistakes made in relaying on computers can be amusing: at one point we noticed that the word 'id' was mistakenly tagged by WMatrix software as being about psychology, when in fact it was a frequent mis-typing of 'I' $d$ '. Disambiguation of the meaning of words with multiple semantic functions is essential in this kind of analysis, and has been done where appropriate.

Our qualitative analysis, the method for which is explained in further detail at the time of presentation, represents a descent from the 'aerial view' provided by the statistical overview of word patterns. It allows for a fuller appreciation of individual variability and personal agency, and its findings complement and extend the findings provided by the statistical overview.

\section{Overview of variations}

We begin with an account of word usages that demonstrate the validity of the keyword method in identifying aspects of speech and lifestyle that one would expect to vary across social class categories (Table 1). The numbers in this and other tables in this paper report the number words per 10,000 words of text. For example, the first row of table 1 reports findings for 'em', 'er' and 'um, which occur 103.7 times per 10,000 words in the high SEC men's text, and 131.7 times per 10,000 words in the low SEC men text. The three asterisks (***) after the 131.7 means this is a statistically very significant difference between men. There is also a highly significant difference between high and low SEC women. The 0.0001 at the end of this first row means that the overall male/female difference on this item is very significant, and since it is in bold it is women who use this more than men. In this, as for all tables, significance tests are based on a log likelihood test.

\section{Table 1: Informal English and lifestyle}

The table shows that low SEC people are considerably more likely to use informal English and this holds true for both genders. The 'lifestyle' words show that high SEC men like to talk about golf, politics and meetings more than other people. High SEC women, on the other hand, are more interested in musical activities. The words referring to drinks, though not particularly common in the corpus, show that low SEC women are particularly likely to mention drinking tea, high SEC men to mention 
drinking wine, and men of both SEC groups to be somewhat more likely to talk about beer and pubs, with low SEC men contributing more to this count than high SEC men (though the difference between men is not statistically significant). Reading, books and newspapers are particularly unlikely to be mentioned by low SEC men.

\section{'Women's language'}

One of the key claims of the variationist paradigm is the identification of talk about feelings, other people, and the use of 'boosters' as features particular to 'women's language'. We have argued that this paradigm has largely neglected to consider the interaction of gender with socio-economic status. The first part of Table 2 shows the findings for words associated with these things.

\section{Table 2: Feelings, boosters, people and interpersonal communication}

The 'feelings' and 'booster's sections of the table show that talking about crying and being upset or fearful, and the use of boosters are more likely to occur in women's interviews. Within this, though, there are differences by SEC, the most marked of which relate to differences between high and low SEC women, where high SEC women are particularly likely to use boosters and to talk about being scared or fearful. Both of these are commonly reported in the 'gender differences' paradigm as typical of women generally, but these findings suggest that it is higher SEC women who contribute most of this difference.

Clearly, too, men are not averse to speaking about emotions, although use of terms like 'emotion' or 'depression' perhaps position emotion as a topic for commentary, rather than being expressions of feeling at the time of interview. Swear words, though, are more likely to be direct expressions of feeling and the 'angry/annoyed' words can be thought of as having a similar status in this respect as 'scared/shocked'. References to anger and annoyance are particularly common in low SEC men, using swear words particularly common in high SEC men. The finding that men swear more than women replicates other sociolinguistic studies, but these normally show men of low social class swearing more (Rayson et al., 1997; McEnery and Xiao, 2004). In this respect the findings of McEnery and Xiao (2004) that this overall gradient masks a somewhat curvilinear relationship between social class and swearing is of interest, largely because of the explanation that they proffer: 'those in authority flout their seniority through the use of swear words' (2004: 245). We return to this in the conclusion.

Orientation towards both self revelation and towards other people is commonly regarded as a characteristic of women and women's speech in the gender differences paradigm. Table 2 shows that the picture is modified by the introduction of SEC. Clearly, in most cases women are more likely to use words reflecting these orientations than men, with low SEC women being particularly ' $\mathrm{I} / \mathrm{me}$ ' centred in their speech, as well as more family centred than high SEC women. High SEC men stand out as being particularly uninterested in talking about other people, apart from their wives, on whom they seem to be quite centred. They are, though, more likely than low SEC men to be 'I/me' centred, suggesting a greater propensity for self-revelation. Our data suggests, in fact, that low SEC people contribute most to the overall gender difference on ' $\mathrm{I} / \mathrm{me}$ ' centredness that has been so often reported in the literature. A somewhat similar picture is shown by the words associated with interpersonal 
communication, where low SEC women are particularly likely to contribute to the overall gender difference. Gender differences on these words for high SEC men and women are mild or absent.

\section{'Men's language'}

We have seen that men of different SEC groups vary in their talk about feelings, self and other people. A further area for the investigation of interactions between SEC and gender lies in the traditionally 'men's' area of information, choice and control. Table 3 shows relevant findings, suggesting that high SEC men are particularly interested in scientific and other factual evidence, in conceiving of the experience of health and illness as a battle in which there is a possibility of success and failure, and in the exercise of control. Thus it appears they consider themselves (and perhaps others) to have a considerable degree of personal agency in the sphere of health and illness, and more so than low SEC men. The finding for question and answers may reflect both this orientation (thus the relatively high use of these by high SEC men) and the additional fact that low SEC women like to talk about interpersonal communications, so use a question and answer vocabulary to explain that dimension of their lives

\section{Table 3: Information, choice and control}

This overview of variations shows that the systematic examination of the interaction between gender and socio-economic status modifies the broad picture gained by comparing overall gender differences. No doubt other variables (for example, ethnicity) would add further knowledge of variability. However, these statistical analyses of word patterns have considerable limitations for developing a detailed understanding of individual variations and for appreciating the subtleties of the particular ways in which people experience their worlds. We have to come down from this 'aerial view' of the gender/SEC landscape, then, and begin to examine things at ground level if we are to appreciate what these features might mean to individuals.

To explore personal meanings at a more detailed, qualitative level we now consider moments in these interviews where there is an explicit orientation to gender ideology. It will be seen that this reveals further intriguing aspects of the interaction of class and gender, as well as demonstrating considerable individual variation and personal agency as people perform their gendered identities in particular ways.

\section{Orientation to gender ideology}

\section{$\underline{\text { Men }}$}

Paragraphs containing any of the words bloke, guy, chap, men, macho, male and masculine and their standard variants (eg: blokes, masculinity) were retrieved and high and low SEC men were compared in a qualitative analysis aimed at identifying references to gender ideology. In particular, we were interested in identifying identities that departed from 'hegemonic' masculinity, and whether these were located in one SEC group rather than another. High and low SEC men did indeed differ on this dimension.

While some high SEC men revealed a conventional 'hegemonic' orientation, rehearsing conventional gender stereotypes ('I don't think men generally talk so 
much' (EAP37) 'most of us think about [weight training] if you're a male' (CP27)), others departed markedly from this. This was sometimes presented as a straightforward response to the threat posed by illness:

They say in the macho thing big men don't cry and things but it was six foot six friends coming to see me after the hospital and one of them gave me a huge hug and started crying you know. (IC33)

One man with depressive illness described a 'pretty macho, tough environment' at school and recollected his experience of going for therapy:

sort of walking in, and you're surrounded by pale skinny fucking anorexics you know and you just think A. I'm a bloke, B. I'm not one of you lot....You know, I looked around the room and there was these sobbing anorexics and I'm just thinking fuck you, you know what am I doing here? And you get in there and there's the little box of tissues and you just think oh piss off. And "How did you feel?" and all that stuff, that's how I felt it was just like my whole thing was completely negative about it. So you can see where I was coming from. It's not easy for blokes, especially not blokes from that kind of background. (DP04)

But he eventually accepted therapy and felt that it had changed his ideas about masculinity, so that now he reflected:

it sort of depends on what your models of masculinity are. I mean I think one of the problems is that you sort of lack a kind of middle ground between being kind of really macho and emotionless, and kind of tough for want of a better word, or kind of emotionally constipated which I kind of put together, do you know what I mean? And then the other thing you don't want to be is a kind of wet bugger, you know you don't want to be kind of, you know the kind of world I came from was pretty, you know I went to a boys' school it was pretty rough [laughs]. You know it had its rough old moments, and it wasn't the kind of place you admitted vulnerability, and I suppose that's what going to therapy is about. (DP04)

Two other high SEC men self-identified as gay and associated this with critical perspectives on conventional masculinity and a personal willingness to use 'women's language':

it is still very easy for me to talk about my feelings. About how I feel or to make a comment on other people if I find they are beautiful or whatever you know. (DP07)

one priest in particular, no in fact all of them in their very different ways from young men to, to [um] much older men, have all of them in their ways been very loving and caring and supportive both to me and my partner through the bad times as well as the good. And yes, they've been [um] very loving and very caring (DP16 our italics) 
Kiesling (2005) has shown that one of the tasks that heterosexual men often face in expressing homosocial desire (in our terms, the wish for emotionally supportive relationships with other men) is to manage the potential threat that the need for intimacy poses for secure identification as heterosexual. In his analysis of fraternity culture in American universities, Kielsing shows how this enables men to successfully resolve this conflict, so that it becomes possible for a fraternity leader to announce to other members in a public meeting 'I love you all' without attracting the perception that he is expressing homosexual desire (2005: 710).

We found the same thing in the story of one high SEC man, a 53 year old company chairman and ex paratrooper, much of whose self-presentation appeared designed to generate a performance of stereotypically masculine identity, as where he said he was as a 'go get 'em type of guy' who had decided to 'fight' his illness rather that give in to it. He described a 'group of guys' from work with whom he had lost touch who, when they heard about his illness, came to see him regularly 'and we go out for a beer and you know it's great you know it's fantastic' (LC02). Perhaps because of the security with which this performance of conventional masculinity was established it was, in the same way as it was for Kiesling's fraternity leader, then possible to make some markedly 'feminine' linguistic choices. He indicated that he had been 'hugged and kissed by all sorts of people, men as well as women.' He described a man who had helped him plan his funeral service as 'an absolute poppet, fantastic.' $\mathrm{He}$ described the doctor who told him about the terminal nature of his illness as 'so gentler...very sympathetic, very caring.' He 'still relished seeing' this 'fantastic' and 'very supportive' oncologist and ended his description of this man by saying 'I love the guy, he's a great guy.'

Low SEC men, by contrast, displayed no such alternative performances of masculinity, apart from one who, in a somewhat self-parodying way, described his approach to crying:

Yes I will cry. I don't very often... I'm certainly more affected by something of that nature now than I ever was yes. I always used to think that I was the macho man that you know I didn't cry, no I went in head down, knuckles, knuckles to the front. Don't believe it - women are stronger than men! (HF01; 65 year old butcher)

Another low SEC man, a 59 year old builder, like the high SEC company chairman above described admiringly how a male doctor had told him the news of his terminal illness, but chose very different adjectives ('brilliant', 'excellent', 'really good') to convey the doctor's qualities. Taken together, the findings of this section and the earlier quantitative analysis suggest that high and low SEC men differed in their performances of gendered identity, with high SEC men exhibiting a more varied repertoire.

\section{$\underline{\text { Women }}$}

Paragraphs containing any of the words lady, girl, feminine, female and women and their standard variants (eg: girls, femininity) were retrieved and high and low SEC women were compared in a qualitative analysis aimed at identifying references to 
gender ideology and evidence of departures from conventional models of feminine identity.

It was immediately apparent for both groups of women that illness was not experienced as a threat to conventional femininity by the majority of these women. Rather, it appeared to be the opportunity for an intensification of reliance on existing networks of female friends and relatives for emotional and practical support.

Occupancy of this 'support group' culture was significantly greater in the worlds of lower SEC women.

It was striking how frequently the word 'lovely' was used by low SEC women, particularly in the frequency with which this adjective was applied to other women. Following this lead, we therefore returned to the entire interview text to examine the distribution and uses of this word. It was used 27 times by men (15 high SEC; 12 low SEC), with just four of these being applied to another person (one a gay man describing 'lovely Filipino boys'). Women, on the other hand, used the word 108 times. High SEC women, with 30 instances, applied the word to other people eight times. Low SEC women used the word 78 times, with 39 of these instances being applied to other people (12 to men; 27 to other women). Nurses were the category of person that the adjective was applied to most frequently (7 times). Some typical examples are as follows:

I had two lovely nurses, support nurses at the hospital.

My oncologist was a charming man, a lovely lovely man

I have a lovely, lovely man, well he's a young boy he is, [a fitness] trainer

She [my mum] was very good to me, wonderful, she was a lovely lady,

My boss is lovely, she's lovely and she was really worried.

one of the nurses was very into sort of alternative medicine and if she had a spare half hour she used to come and do my feet for me. And she sent me to sleep on two or three occasions in the middle of my treatment and that you know. That was really wonderful, I still keep in touch with that one, she's lovely.

Ten instances of the word 'lovely' in the low SEC corpus were applied not to people, but to the experience of having complementary therapy, in which aromatherapy, reflexology, foot massage, Indian head massage and relaxation tapes played a part.

The professional accomplishment of being 'nice' and 'friendly' by nurses has been identified as an important component of the care of people with serious illness in several studies (Hunt, 1991; Li, 2004) and the association of this with the practice of complementary therapies by nurses - particularly those that involve massage and aromatherapy - has been established by Garnett (2003). Other evidence (Doel and Segrott, 2003; Seale et al., 2007)) has shown that complementary therapies of this sort, which provide intimate, soothing physical contact, are an important element of women's health culture, promoted particularly through magazines and newspapers 
(such as the UK's Daily Mail) that serve a middle aged and working or lower middle class readership.

Returning to the retrieved paragraphs that we started with, it was noticeable too that low SEC women put some effort into distinguishing different kinds of other women, categorising them according to whether they were likely to be supportive or not. Thus a 'girl on the end of the phone' who was unhelpfully responding to an inquiry has to be replaced by another person after the interviewee had 'asked to speak to somebody else' (PC41). Distinguishing between 'horrible girls' and 'true friends' while at school was the lynch pin of one woman's (EP12) recollections of her school days.

Additionally, some low SEC women exhibited a preference for female doctors because of concerns about personal privacy. Thus a 47 year old secretary with chronic pain spoke of the relief she had experienced after her hysterectomy from the 'dreaded monthly visits ladies have', adding:

I like the lady doctor that's [at my GP practice]. She's not my actual registered GP but I see her sometimes if it's like women's problems or something like that, that I'd rather speak to a woman about. (CP12)

Several comments from low SEC women suggested that powerful men were approached carefully, and their degree of benevolence monitored closely. Evident in a number of stories about interactions with male doctors, there was a further instance where a woman, a retired secretary, spoke approvingly of the approach taken by her male boss towards the employment conditions of the female fixed-term contract research workers that he employed:

He always stuck his neck out for people. If he had people that he felt were doing a good job. I mean for instance there was a researcher who, I mean, you know what the short term contracts are like, the women aren't entitled to maternity leave or anything like that if there were on those. And she was employed on a particular fund, and when she had [um] she needed maternity leave, he took her off that fund, put her on another one so she could have her maternity leave. (DP12)

If, on the other hand, a man in a position of power failed to exhibit appropriate behaviour he was, like obstructive 'girls' on the end of phone lines, subjected to criticism, as where a woman recalled a doctor who could not remember her name or her details:

and I think, oh at least have the courtesy to read my notes before you call me in. And er understand that it's me you're talking to. (PC02; 61 year old accounts manager)

Low SEC women, then, demonstrate a rather conservative orientation towards gender ideologies, being quite uncritical of conventional gender stereotypes and showing, in their own experiences of illness, a strong attachment to a 'support group' culture. This involves the identification of sources of support and the scrutiny of others' behaviour for signs of lack of supportiveness which, if detected, is subject to moral opprobrium. There is little to suggest desire to depart from conventional ways of performing gender roles and identities. 


\section{Discussion}

The overview of word distributions indicates that gender and socio-economic category interact in ways that have not always been recognised by those who focus on overall gender differences alone. Keyword analysis is quite effective in identifying elements of lifestyle and styles of speech that one might expect to vary by gender and social class. The findings about feelings and boosters suggest that high rather than low SEC women are largely responsible for the propensity to talk about fearfulness and to use superlatives, modifying the commonly expressed view from within the variationist paradigm that this is a characteristic of 'women's talk' in general (Coates 2004) and suggesting that this tradition may have placed excessive reliance on samples of people of higher social standing.

It is clear, too, that the predominance in women's speech of talk about other people and of self revelation, often reported in variationist literature as a general characteristic separating men and women, must be modified. High SEC men are, by comparison with low SEC men, relatively ' $\mathrm{I} / \mathrm{me}$ ' centred in their speech. It is high rather than low SEC men who are largely responsible for the overall gender differences in producing a 'command and control' discourse in relation to managing illness. These findings suggest support for Cameron's (2003) view that men with more cultural capital are likely, given contemporary language ideologies, to deploy selected aspects of 'women's language' and this may be associated with the maintenance of power.

The qualitative analysis of orientations to gender ideology is similarly revealing of the interaction of class and gender. In general, men are more likely to experience illness as a threat to the performance of the type of masculine identity that emphasises success in the public sphere because of the undermining consequences of illness. Arguably, an interview situation requiring a degree of self revelation and emotional openness may also be an environment that challenges 'hegemonic' masculine norms (Connell, 1995) that value emotional indirectness. Within this, though, high SEC men are of particular interest. They exhibit more variability in their personal performances of masculinity and display a more reflexive and critical perspective on conventional masculinity than low SEC men, again suggesting that their greater cultural capital involves access to a wider discursive repertoire. Additionally, their considerable willingness to swear and to perform a gay identity in this somewhat public context of an internet-broadcasted research interview may reflect their greater confidence in breaking with taboo as a marker of distinction (Bourdieu, 1984).

Women of both SEC groupings experienced illness, and the interview setting, not as a threat to conventional gendered expectations, but as the opportunity for a confirmation of the 'support group' culture to which most appeared already committed. The detailed performance of this by low SEC women in particular was traced out. These women appear willing to accept relationships with other men and women, and a performance of gendered identity that perhaps their high SEC counterparts would find uncomfortably gender-stereotyped. These appear to be rooted in a somewhat moralising discourse on what kinds of behaviour are acceptable within women's support group culture, and a considerable degree of acceptance of 
conventional gendered power relations. This is complemented with a statistical analysis that paints a picture of low SEC women as more family and ' $\mathrm{I} / \mathrm{me}$ ' centred than high SEC women, with a marked preference for interpersonal methods of communicating.

Our analysis demonstrates support for both a performative or agentic view of gender and for the view that social structural considerations exercise a somewhat determinative influence over these performances. The people we have studied did not participate in face to face communities of practice (Lave and Wenger, 1991) because they did not know each other, being selected as a research sample. But their class and gender position appears to have influenced some common orientations towards popular and mass mediated cultural understandings of how to perform identities, which clearly vary quite systematically across the different groupings. These were, then, perhaps 'imagined' communities of practice in the sense in which Anderson (1991) has used the term.

Clearly, too, this study is specific to the particular context in which the texts were produced: research interviews designed to elicit illness narratives. Serious illness is particularly likely to involve re-thinking priorities and, for some, a change in orientation to gendered norms (Emslie et al., 2006). High SEC men may be particularly self-revelatory in the context of a one-to-one interview in which they are invited to talk about their illness experiences, but it is not necessarily the case that they would be in some other context. People vary not only between each other in their performances of identity, but also across different settings in which the 'same' person might be involved. We encourage further investigations of the interaction of class and indeed other variables with gender in other local contexts.

\section{Acknowledgements}

This study was supported by a grant from the UK Economic and Social Research Council (RES-062-23-0130). We are grateful to them, to the DIPEx organisation who collected the original interviews, to Sue Ziebland who offered helpful comments on drafts of this paper and to the interviewees who participated.

\section{References}

Anderson, B. (1991) Imagined Communities. London: Verso Books.

Bergvall, V.L. (1999) 'Toward a Comprehensive Theory of Language and Gender', Language in Society 28: 273-293

Billig, M. (1988) 'Methodology and Scholarship in Understanding Ideological Explanation', in Antaki, C. (ed.) Analysing Everyday Explanation: A Case Book of Methods. London: Sage

Bourdieu, P. (1984) Distinction: A Social Critique of the Judgement of Taste. London: Routledge

Bourdieu, P. (1986) 'The Forms of Capital', in: Richardson, J.G. (ed.) The Handbook of Theory: Research for the Sociology of Education, pp. 241-258. New York:

Greenwood Press 
Cameron, D.(2003) 'Gender and Language Ideologies', in Holmes, J. and Meyerhoff, M. (eds) The Handbook of Language and Gender, pp. 447-467. Oxford: Blackwell

Coates, J. (2004) $3^{\text {rd }}$ edition. Women, Men and Language: A Sociolinguistic Account of Gender Differences in Language. Harlow: Pearson

Connell, R.W. (1995) Masculinities. St Leonards, NSW: Allen and Unwin.

Doel, M.A. and Segrott, J. (2003) 'Self, Health and Gender: Complementary and Alternative Medicine in the British Mass Media', Gender, Place and Culture 10(2): $131-44$

Eckert, P. (1990) 'The Whole Women:Sex and Gender Differences in Variation', Language Variation and Change 1: 245-267.

Eckert, P. and Wenger, E. (2005) 'Communities of Practice in Sociolinguistics', Journal of Sociolinguistics 9(4): 582-589

Emslie, C., Ridge, D., Ziebland, S. and Hunt, K. (2006) 'Men's accounts of depression: Reconstructing or resisting hegemonic masculinity?' Social Science and Medicine 62(9): 2246-2257

Freed, A. (1992) 'We Understand Perfectly: A Critique of Tannen's View of Miscommunication', in Hall, K., Bucholz, M. and Moonwomon, B. (eds) Locating Power: Proceedings of the Second Berkeley Women and Language Conference, pp. 144-152. Los Angeles: University of California

Garnett, M. (2003) 'Sustaining the Cocoon: The Emotional Inoculation Produced by Complementary Therapies in Palliative Care', European Journal of Cancer Care 12(2): 129-136.

Giddens, A. (1994) The Transformation of Intimacy: Sexuality, Love and Eroticism in Modern Societies. Cambridge: Polity Press.

Hunt, M.W. (1991) 'Being Friendly and Informal: Reflected in Nurses', Terminally Ill Patients' and Relatives' Conversations at Home', Journal of Advanced Nursing 16: 929-938

Kiesling, S.F. (2005) 'Homosocial Desire in Men's Talk: Balancing and Re-creating Cultural Discourses of Masculinity', Language in Society 34: 695-726

Lakoff, R. (1975). Language and Women's Place. New York: Harper and Row.

Lave, J. and Wenger, E. (1991) Situated Learning: Legitimate Peripheral Participation. Cambridge: Cambridge University Press

Li, S. (2004) 'Symbiotic Niceness: Constructing a Therapeutic Relationship in Psychosocial Palliative Care', Social Science and Medicine 58(12): 2571-83 
McEnery, A. and Xiao, Z. (2004) 'Swearing in modern British English: the case of fuck in the BNC', Language and Literature 13(3): 235-268

Rayson, P. (2005) 'Wmatrix: A Web-based Corpus Processing Environment', Computing Department, Lancaster University.

http://www.comp.lancs.ac.uk/ucrel/wmatrix/

Rayson, P., Leech, G. and Hodges, M. (1997) 'Social differentiation in the use of English vocabulary: some analyses of the conversational component of the British National Corpus',. International Journal of Corpus Linguistics 2(1): 133-152.

Rose, D. and Pevalin, D.J. (2005) The National Statistics Socio-economic Classification: Origins, Development and Use. Basingstoke: Palgrave-Macmillan.

Savage, M. (2000) Class Analysis and Social Transformation. Buckingham: Open University Press

Scott, M. (2005). Wordsmith Tools 4.0 Oxford: Oxford University Press. (Available at http://www.lexically.net/wordsmith/version4/)

Seale, C., Boden, S., Lowe, P., Steinberg, D. and Williams, S. (2007) 'Media Constructions of Sleep: A Study of UK National Newspapers' Social Science and Medicine (in press)

Seale, C., Charteris-Black, J. and Ziebland, S. (2006) 'Gender, Cancer Experience and Internet Use: A Comparative Keyword Analysis of Interviews and Online Cancer Support Groups', Social Science and Medicine 62: 2577-2590

Speer, S. (2005). Gender Talk: Feminism, Discourse and Conversation Analysis. London: Routledge.

Stokoe, E. and Weatherall, A. (2002) 'Gender, Language, Conversation Analysis and Feminism', Discourse and Society, (special issue) 13(6):707-864.

Talbot, M.M. (2003) 'Gender Stereotypes: Reproduction and Challenge' in Holmes, J. and Meyerhoff, M. The Handbook of Language and Gender, pp. 468-486 Oxford: Blackwell

Townsend. P. and Davidson, N. (1982) Inequalities in Health. Harmondsworth: Penguin 
Table 1: Informal English and lifestyle (words per 10,000)

\begin{tabular}{llll}
$\begin{array}{l}\text { Men } \\
\text { High Low }\end{array}$ & \multicolumn{2}{l}{ Women } & Overall \\
High Low & $\begin{array}{l}\text { gender } \\
\text { compared }^{\$}\end{array}$ \\
242.5 & 192.3 & 235.0263 .6 & $\mathrm{p}<$
\end{tabular}

Total words (thousands) $\quad 242.5 \quad 192.3 \quad 235.0263 .6 \quad \mathrm{p}<$

Informal English

Em/er/um

$103.7131 .7 * * *$

$101.3155 .6^{* * *} \quad \mathbf{0 . 0 0 0 1}$

Aye/wee ${ }^{\&}$

$0.67 .0 * * *$

$\begin{array}{lll}0 & 1.0 * * * & 0.0001\end{array}$

Cos/'ve/'ll

$11.121 .3 * * *$

$8.619 .4 * * *$

n.s.

Lifestyle

Golf/politics/meetings

$3.4 * * * 0.5$

$0.5^{*} \quad 0.1$

0.0001

music/piano/choir

$0.7 \quad 0.3$

$1.2 * 0.4$

n.s

tea

$0.6 \quad 0.6$

$0.5 \quad 1.4^{* *}$

n.s.

beer/pub

$0.5 \quad 0.7$

$0.3 \quad 0.3$

0.01

wine

$0.7 \quad 0.3$

$0.1 \quad 0.2$

0.01

$\mathrm{read} /$ books/newspaper

$6.3^{*} \quad 4.4$

$7.6 \quad 8.3$

0.0001

\& disambiguated from 'wee' as in urine

* $\quad \mathrm{p}<0.01$ for SEC comparison within gender

** $\quad \mathrm{p}<0.001$ for SEC comparison within gender

$* * * \quad \mathrm{p}<0.0001$ for SEC comparison within gender

$\$ \quad$ Bold women more; italics men more

Table 2: Feelings, boosters, people and interpersonal communication (words per 10,000)

\begin{tabular}{|c|c|c|c|c|c|}
\hline 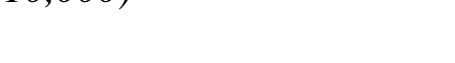 & Men & & Womer & & Overall \\
\hline & High & Low & High & Low & $\begin{array}{l}\text { gender } \\
\text { compared }^{\$}\end{array}$ \\
\hline Total words (thousands) & 242.5 & 192.3 & 235.0 & 263.6 & $\mathrm{p}<$ \\
\hline Feelings & & & & & \\
\hline $\begin{array}{l}\text { I feel/felt/feeling }{ }^{\&} \\
\text { Cry/ Upset / miserable }\end{array}$ & 17.7 & 16.2 & 18.7 & 17.6 & n.s. \\
\hline Traumatic & 4.7 & 4.0 & 5.2 & 6.2 & 0.01 \\
\hline Scare/shock/fright/fear & 5.1 & 5.0 & $9.3 * * *$ & 5.2 & 0.0001 \\
\hline Emotion & $2.4 * *$ & 1.0 & 1.0 & 1.7 & n.s. \\
\hline Depressed/depression/ & & & & & \\
\hline Depressive & 12.3 & 10.3 & $8.6^{* * *}$ & 5.3 & 0.0001 \\
\hline Shit/fuck/bloody & $2.1 * * *$ & 0.4 & 0.3 & 0.2 & 0.0001 \\
\hline $\begin{array}{l}\text { Angry/annoyed/frustrated } \\
\text { disappointed }\end{array}$ & 2.3 & $4.6 * *$ & 3.1 & 2.4 & n.s. \\
\hline $\begin{array}{l}\text { Boosters } \\
\text { incredible/y, amazing/ed/ly } \\
\text { awful/ly, particularly, } \\
\text { huge/ly, enormous/ly, } \\
\text { horrible, actually, really }\end{array}$ & 60.4 & 61.8 & $96.8 * *$ & $* 64.6$ & 0.0001 \\
\hline
\end{tabular}




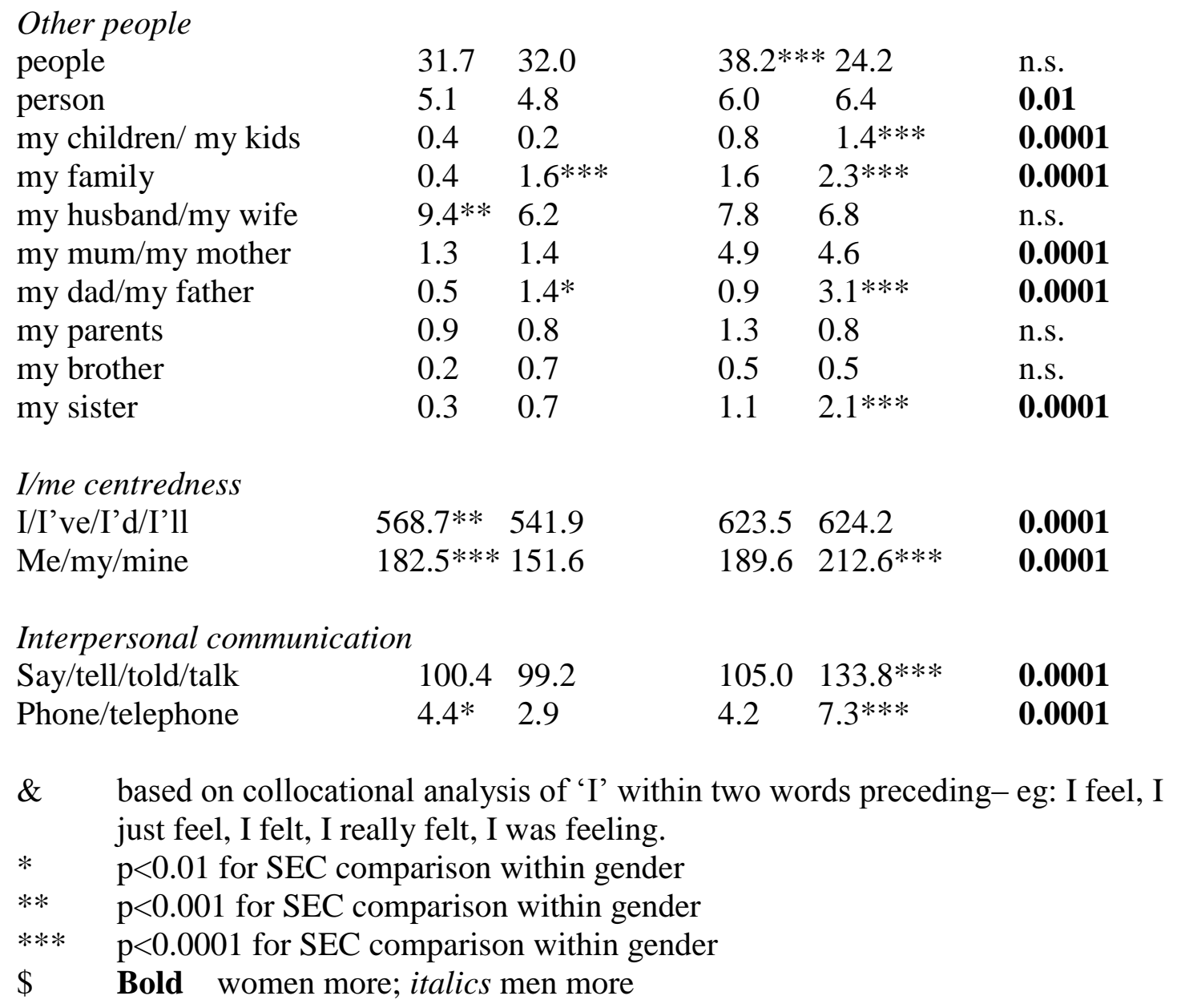

Table 3: Information, choice and control (words per 10,000)

\begin{tabular}{lll} 
Men & \multicolumn{1}{c}{ Women } & Overall \\
High Low & High Low & gender
\end{tabular}

\begin{tabular}{|c|c|c|c|c|c|}
\hline Total words (thousands) & 242.5 & 192.3 & 235.0 & 263.6 & $\begin{array}{l}\text { coml } \\
\mathrm{p}<\end{array}$ \\
\hline Choice/choose/options & 1.7 & 1.6 & 1.3 & 1.3 & n.s. \\
\hline Control/plan & $5.2 * * *$ & 1.8 & 3.5 & 2.5 & n.s. \\
\hline Success/in control/fail & $4.7 * *$ & 2.5 & 2.9 & 1.9 & 0.001 \\
\hline $\begin{array}{l}\text { Beat/fight/battle/lose } \\
\text { facts, factually, in fact, } \\
\text { discussed, internet, web, } \\
\text { web site, science, evidence, } \\
\text { findings }\end{array}$ & $7.9 * * *$ & 4.7 & 6.9 & 7.2 & n.s. \\
\hline $\begin{array}{l}\text { Question/advice/answer } \\
\text { /explain/explanation }\end{array}$ & $12.5^{*}$ & 10.0 & 10.8 & $13.9 *$ & n.s \\
\hline
\end{tabular}

* $\quad \mathrm{p}<0.01$ for SEC comparison within gender

$* * \quad \mathrm{p}<0.001$ for SEC comparison within gender

$* * * \quad \mathrm{p}<0.0001$ for SEC comparison within gender

$\$$ Bold women more; italics men more 